\title{
Primary Pulmonary Squamous Cell Carcinoma Associated with Elevated IL-6, Leukocytosis, Hypercalcemia, Phagocytosis, Reactive Lymphadenopathy and Glomerular Mesangial Cell Proliferation via the Production of PTH-rP and G-CSF
}

Shin Takaoka, Yuko Yamane, Masateru Nishiki, Toru Yamaguchi and Toshitsugu Sugimoto

\begin{abstract}
We report an autopsied case of a 74-year-old man with primary pulmonary squamous cell carcinoma (SCC) associated with leukocytosis, hypercalcemia, phagocytosis in the bone marrow, reactive lymphadenopathy and mesangial cell proliferation in the glomerulus. Laboratory examination revealed increased serum levels of parathyroid hormone-related peptide (PTH-rP), granulocyte colony stimulating factor (G-CSF), interleukin-6 (IL-6) and soluble interleukin 2 receptor (s-IL2R). An autopsy showed moderately differentiated SCC at the left lower lobe of the lung, of which tumor cells distinctly showed cytoplasmic immunoreactivity to anti-G-CSF and anti-PTH-rP antibodies. Thus, pulmonary SCC seemed to produce both G-CSF and PTH$\mathrm{rP}$, causing leukocytosis, hypercalcemia, and IL-6 production from the bone. IL-6 also might have stimulated the proliferation of SCC and glomerular mesangial cells, and induced phagocytosis, reactive lymphadenopathy and hepatosplenomegaly by interacting with the mononuclear phagocytic system.
\end{abstract}

Key words: squamous cell carcinoma, parathyroid hormone-related peptide, granulocyte colony stimulating factor, interleukin-6, glomerular mesangial cells, hemophagocytic syndrome

(DOI: 10.2169/internalmedicine.47.0155)

\section{Introduction}

Leukocytosis and hypercalcemia are often found in patients with cancer. Recent studies have demonstrated that either granulocyte-colony stimulating factor (G-CSF) or parathyroid hormone-related peptide (PTH-rP) could be produced by cancer cells (1-6). Furthermore, cancer cells may produce not only G-CSF but also multiple other cytokines such as interleukin (IL)-1, IL-6, IL-8 and M-CSF (7-9). Here, we report an autopsied case of primary pulmonary squamous cell carcinoma (SCC) associated with leukocytosis, hypercalcemia, hemophagocytosis, reactive lymphadenopathy and diffuse glomerular mesangial proliferation via the production of PTH-rP, G-CSF and IL-6.

\section{Case Report}

A 74-year-old Japanese man was admitted to Shimane University Hospital due to poor appetite, decreased body weight and general fatigue. Physical examination revealed lymph node swelling in the bilateral cervical and inguinal regions. Breath sound was markedly diminished in the left lower chest.

The laboratory findings are summarized in Table 1. Circulating leukocyte counts increased to $42,520 / \mu 1$, in which segmented neutrophils comprised $94 \%$. A serum tumor marker, a SCC antigen, was elevated, and sputum cytology revealed SCC. Serum levels of PTH-rP, G-CSF, IL-6, LDH, ferritin and soluble interleukin 2 receptor (s-IL2R) were also increased. Bone marrow biopsy revealed numerous hemophagocytes and toxic granulocytes (Fig. 1), suggesting the 
Table 1. Laboratory Findings on Admission

\begin{tabular}{|c|c|c|c|c|c|c|}
\hline \multicolumn{2}{|c|}{ 《Urinalysis》 } & \multicolumn{3}{|c|}{ 《Blood Chemistry》 } & \multicolumn{2}{|c|}{$\langle\langle$ Immunological examination $\rangle$} \\
\hline Pro. & + & TP & 7.6 & $\mathrm{~g} / \mathrm{dl}$ & Ferritin & $\mu \mathrm{g} / 1$ \\
\hline Blood & + & $\mathrm{Alb}$ & 2.6 & $\mathrm{~g} / \mathrm{dl}$ & CRP & $\mathrm{mg} / \mathrm{dl}$ \\
\hline Sediment & & GOT & 13 & $\mathrm{IU} / 1$ & SCC & $\mathrm{ng} / \mathrm{ml}(<1.5)$ \\
\hline RBC 2 & $0-29 / 1 \mathrm{~F}$ & GPT & 19 & $\mathrm{IU} / 1$ & s-IL2R & $\mathrm{U} / \mathrm{ml}(246-742)$ \\
\hline 《Peripheral & Blood》 & LDH & 1944 & $\mathrm{IU} / 1$ & Intact-PTH 5.6 & $\mathrm{pg} / \mathrm{ml}(11-54)$ \\
\hline WBC 42 & $520 / \mu 1$ & ALP & 501 & $\mathrm{IU} / 1$ & PTH-rP $\quad 132.2$ & $\mathrm{pmol} / \mathrm{l}(13.8-55.3)$ \\
\hline Myelo. & $0.5 \%$ & BUN & 24.9 & $\mathrm{mg} / \mathrm{dl}$ & G-CSF & $\mathrm{pg} / \mathrm{ml}(<18.1)$ \\
\hline Seg. & $94 \%$ & Crea & 0.98 & $\mathrm{mg} / \mathrm{dl}$ & $\mathrm{IL}-6$ & $\mathrm{pg} / \mathrm{ml}(<4)$ \\
\hline Mono. & $4.0 \%$ & $\mathrm{Ca}$ & 11.8 & $\mathrm{mg} / \mathrm{dl}$ & IL-1 $\beta$ & $\mathrm{pg} / \mathrm{ml}(<10)$ \\
\hline Lymph. & $1.5 \%$ & $\mathrm{P}$ & 4.0 & $\mathrm{mg} / \mathrm{dl}$ & TNF- $\alpha$ & $\mathrm{pg} / \mathrm{ml}(1.5-12)$ \\
\hline $\mathrm{Hb}$ & $9.1 \mathrm{~g} / \mathrm{dl}$ & $\mathrm{Fe}$ & 19 & $\mu \mathrm{g} / \mathrm{dl}$ & & \\
\hline Plt 30.9 > & $<10^{4} / \mu 1$ & TIBC & 154 & $\mu \mathrm{g} / 1$ & & \\
\hline
\end{tabular}

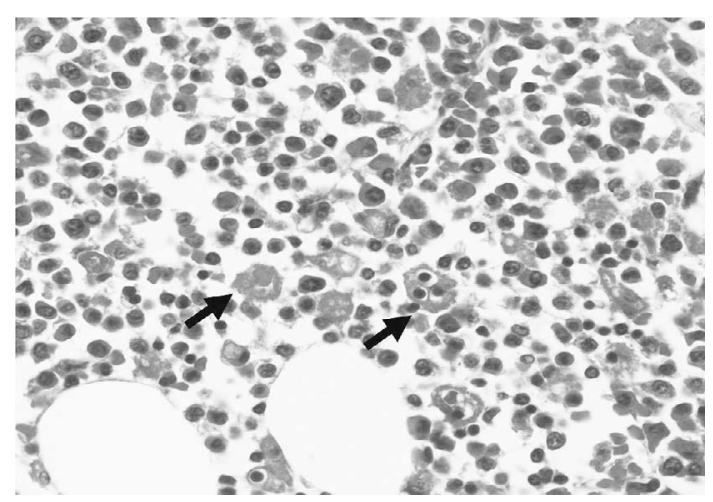

Figure 1. Bone marrow biopsy revealed numerous hemophagocytes (arrow) and toxic granulocytes (Hematoxylin and Eosin staining $\times 400)$.



Figure 2. A chest $\mathrm{CT}$ film revealed a solid mass lesion sized by $4.5 \times 3.8 \mathrm{~cm}$ at $\mathrm{S} 6$ of the left lower lobe of the lung.

involvement of elevated G-CSF and IL-6 levels and the complication of hemophagocytic syndrome. A chest CT film disclosed a solid mass lesion with a size of $4.5 \times 3.8 \mathrm{~cm}$ at $\mathrm{S}$ 6 of the left lower lobe, as well as pleural effusion and mediastinal lymphadenopathy (Fig. 2).

On the 4th day of admission, the patient had complications of severe pneumonia in the right middle lobe, DIC and pulmonary edema. Administration of antibiotics and antifungal agent in combination with gamma globulin was not effective, and he died of respiratory failure on the 7 th day.

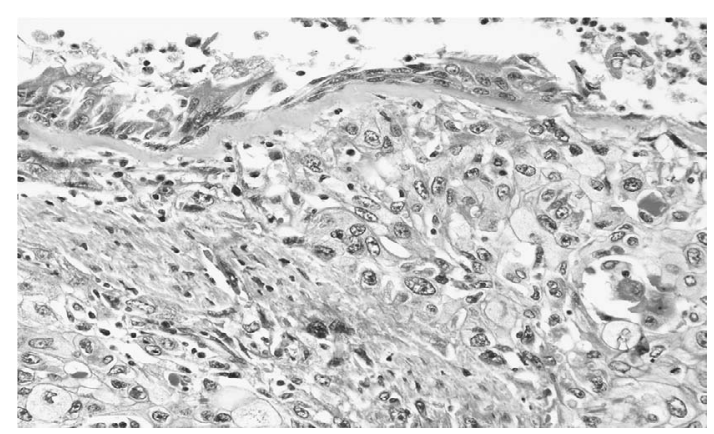

Figure 3. A light microscopic feature of tumor cells in the lung revealed enlarged nuclei compatible for moderately differentiated SCC (Hematoxylin and Eosin staining $\times 200)$.



Figure 4. A light microscopic feature of the glomerulus showed diffuse mesangial proliferation (Hematoxylin and Eosin staining $\times 400)$.

At autopsy, a microscopic examination revealed moderately differentiated SCC in the left lower lobe of the lung (Fig. 3). The tumor was accompanied by diffuse bacterial bronchopneumonia with considerable degrees of surrounding edema and organization, but confined to the lung and not spread to any other lymph nodes or organs. Bilateral interstitial pneumonia with fibrosis and mild hepatosplenomegaly were also noted. Hematoxylin and eosin stain of the kidney showed diffuse mesangial proliferation in the glomerulus (Fig. 4). 


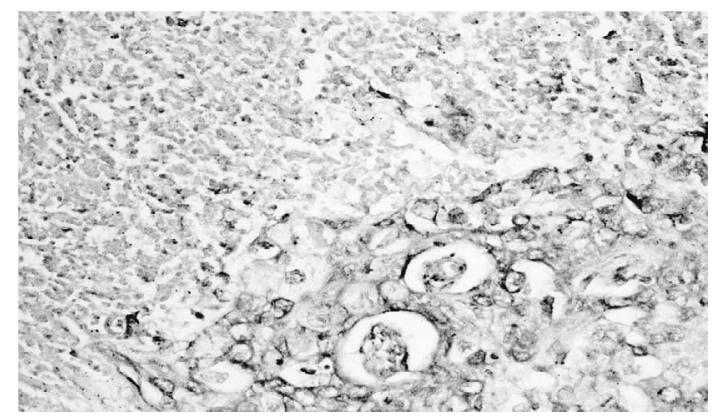

Figure 5. A positive cytoplasmic immunostaining for tumor cells with anti-G-CSF antibody $(\times 400)$.

The lung tumor obtained from autopsy was subject to immunohistochemistry using antibodies against G-CSF and PTH-rP. The sample was fixed with $10 \%$ formaldehyde solution. Then, the fixed tissue was dehydrated in graded ethanols and embedded in paraffin. The tissue block was cut into $5 \mu \mathrm{m}$ slices. The deparaffinized tissue sections were treated with $1 \%$ normal goat serum for 30 minutes and incubated for 60 minutes with monoclonal antibody against GCSF (G-CSF, $\times 10$, Oncogene Science, NY, USA). After washing with phosphate-buffered saline (PBS), the sections were reacted for 30 minutes with horseradish peroxidase conjugated rabbit IgG anti-mouse immunoglobulin and then washed with PBS. An enzymatic reaction was carried out in a solution containing $20 \mathrm{mg}$ of 3.3'-diaminobenzidine- $4 \mathrm{HCl}$ and $0.005 \% \mathrm{H}_{2} \mathrm{O}_{2}$ in $100 \mathrm{ml}$ of Tris buffer, $\mathrm{pH}$ 7.6. Counterstaining was performed with methyl green. The result is shown in (Fig. 5). The tumor cells revealed generalized positive cytoplasmic reactions for G-CSF.

Immunostaining with a PTH-rP antibody (PTHRP 21210.7, $\times 100$, Oncogene Research Product, Boston, MA, USA) was also performed in a similar fashion. After washing with PBS and reacting for 30 minutes with alkaline phosphatase, the antibody activity was detected by the development with naphtol AS-BI phosphate sodium salt as a substrate and hexazotized new fuchsin as a coupler (10). An enzymatic reaction was carried out in DAKO Target Retrieval Solution, $\mathrm{pH} 6.0,95^{\circ} \mathrm{C}, 40$ minutes. Counterstaining was performed with red. The tumor cells revealed generalized positive cytoplasmic reactions for PTH-rP (Fig. 6A). In contrast, immunostainings with normal mouse IgG1 (Caltag Laboratories, Burlingame, CA, USA) showed negative reactions, eliminating the possibility of nonspecific binding of antibodies (Fig. 6B).

\section{Discussion}

G-CSF is one of the hematopoietic growth factors that causes leukocytosis. More than 30 cases of G-CSFproducing lung cancer have been reported ever since the identification of the first case with leukocytosis due to GCSF production by lung cancer in 1977 (2). Most of them were histologically SCC and large cell carcinoma. On the other hand, PTH-rP was purified from a human lung cancer-

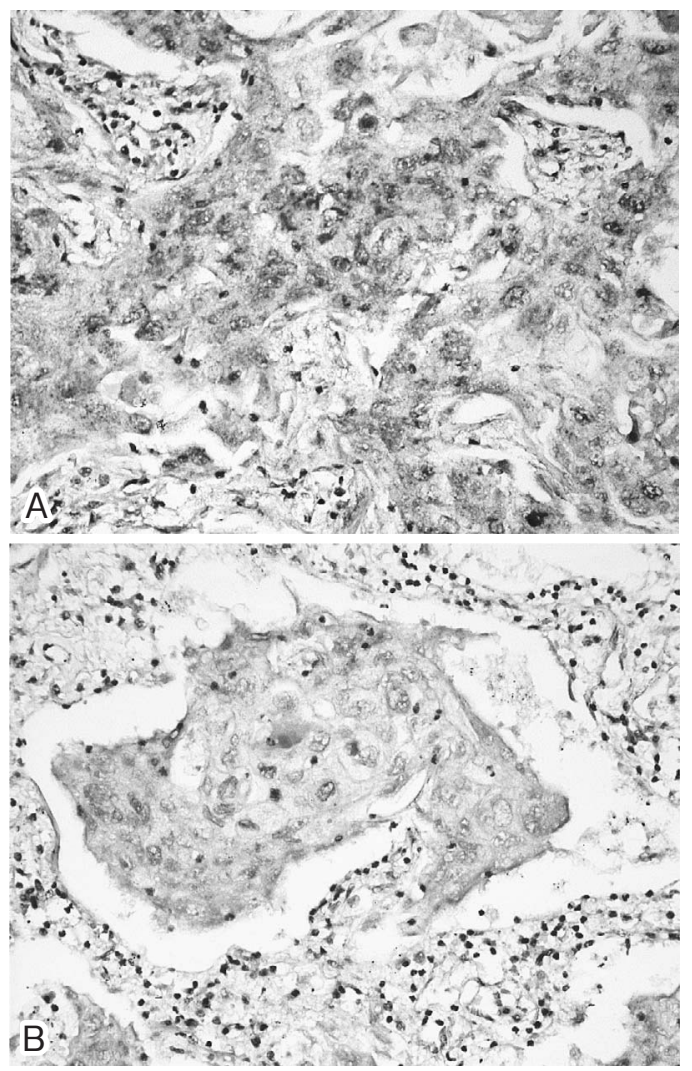

Figure 6. (A) A positive cytoplasmic immunostaining for tumor cells with anti-PTH-rP antibody $(\times 400)$. (B) A negative cytoplasmic immunostaining for tumor cells with normal mouse IgG1 $(\times 400)$.

derived cell line as a causative factor for humoral hypercalcemia of malignancy (HHM), and its primary structure was determined in 1987 (3). HHM is frequently associated with a squamous cell type of lung cancer, and PTH-rP gene expression was demonstrated in it (4). Iguchi et al (5) first reported that high concentrations of PTH-rP were present in the serum of a patient with SCC. The present case showed severe granulocytosis and hypercalcemia as well as elevated serum PTH-rP and G-CSF levels. Furthermore, positive cytoplasmic reactions to antibodies against G-CSF and PTH-rP were shown in SCC at the autopsy. Thus, the patient was diagnosed as primary pulmonary SCC associated with granulocytosis and hypercalcemia possibly via the production of both PTH-rP and G-CSF. It has been reported that patients with lung cancer occasionally have accompanying marked leukocytosis and hypercalcemia (6). However, our literature search revealed that there have only been a few case reports of lung cancer producing both PTH-rP and G-CSF and causing leukocytosis and hypercalcemia to date $(1,11-14)$. All of these patients were Japanese, and such lung cancers might be more prevalent in the Asian ethnic background.

IL-6 is known to differentiate B-cell with the generation of antibodies and to breed and differentiate nerve cells (15). It has been reported that PTH-rP stimulates IL-6 secretion from osteoblasts in bone marrow after binding to its receptor on the cells (16), and that an IL-6 consensus sequence is 
essential in the G-CSF promoter for the response to specific cytokines and mitogens $(17,18)$. Immune staining of autopsy was impossible in the present case. Asanuma et al have also reported that PTHrP producing SCC of the liver was negative for IL- 6 and did not produce this cytokine, but serum level of IL-6 was elevated (19). Thus, it is possible that PTH-rP produced by pulmonary SCC in this case might subsequently stimulate the production of IL- 6 and G-CSF from other organs including bone. Takahashi et al (20) reported that plasma concentrations of TNF-alpha, IL-6 and IL-8 were significantly increased in patients with high PTHrP, in either the presence or absence of hypercalcemia, and that the concentrations of TNF-alpha and IL-6 were also significantly correlated with those of PTHrP. Their observations indicate that high plasma levels of PTHrP in cancerbearing patients contribute not only to the development of hypercalcemia, but also to the development of the syndrome caused by an excess of pro-inflammatory cytokines including IL-6.

The present case was associated with diffuse mesangial proliferation in the glomerulus. This might be explained by increased IL- 6 because it acts as a growth factor for cultured glomerular epithelial cells (21) as well as as mesangial cells in IgA nephropathy (22). This case was also associated with reactive lymphadenopathy, hepato-splenomegaly, and hemophagocytosis in the bone marrow. Although the precise mechanism of such complications remains unclear, increased serum levels of IL-6, s-IL2R, ferritin and LDH might have been responsible. Hemophagocytic syndrome (HPS) is a reactive disorder of the mononuclear phagocytic system, which is primarily or secondarily induced by virus, bacteria, collagen disease and malignant neoplasm. Cytokines and related peptides including IL-6 and s-IL2R play a major role in the pathogenesis of HPS, which are markedly elevated during the acute phase of HPS (23). HPS in the present case seems to be at an acute phase, judged from elevated serum cytokines and reactive proteins. Reactive lymphadenopathy,

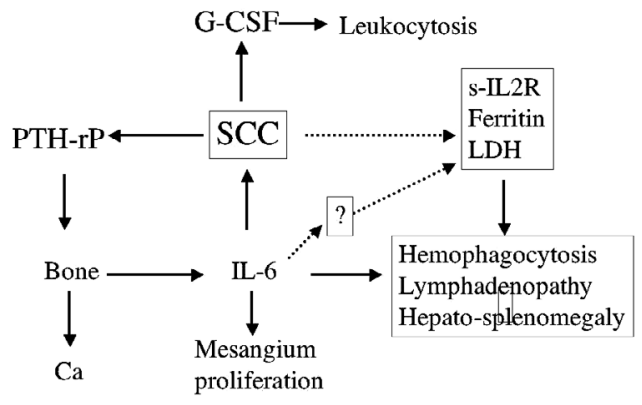

Figure 7. Proposed sequence of events in the present case.

hepatosplenomegaly and hemophagocytosis in this case might be explained by $\mathrm{T}$ cell and macrophage activation due to hypercytokinemia. Molad et al (24) reported the first case of hemophagocytosis induced by pulmonary SCC, in which metastatic cells were found in the bone marrow. However, cancer cells were not found in the bone marrow in the present case, suggesting the primary contribution of the humoral effects of cytokines secreted from pulmonary SCC.

In conclusion, we illustrated the speculated schema of sequence of events occurred in this case (Fig. 7). Pulmonary SCC produced both G-CSF and PTH-rP. PTH-rP in turn stimulated IL-6 release from the bone, and IL-6 subsequently induced mesangial cell proliferation in the glomerulus. IL-6 also adversely stimulated pulmonary SCC and enhanced the production of G-CSF and PTH-rP in a vicious cycle. Moreover, IL-6 as well as activated mononuclear phagocytic system such as increased s-IL2R might have induced hemophagocytosis, reactive lymphadenopathy and hepatosplenomegaly.

\section{Acknowledgement}

This work was supported by grants from the Ministry of Health and Welfare, Japan, and the Shimane University Foundation. We also thank Mrs. Akiko Kawakami for her secretarial assistance.

\section{References}

1. Furihata M, Sonobe H, Iwata J, et al. Lung squamous cell carcinoma producing both parathyroid hormone-related peptide and granulocyte colony stimulating factor. Pathol Int 46: 376-379, 1996.

2. Asano S, Urabe A, Okabe T, Sato N, Kondo Y. Demonstration of granulopoietic factor(s) in the plasma of nude mice transplanted with a human lung cancer and in the tumor tissue. Blood 49: 845852, 1977.

3. Suva LJ, Winslow GA, Wettenhall RE, et al. A parathyroid hormone-related protein implicated in malignant hypercalcemia: cloning and expression. Science 237: 893-896, 1987.

4. Martin TJ, Allan EH, Caple IW, et al. Parathyroid hormone-related protein: isolation, molecular cloning, and mechanism of action. Recent Prog Horm Res 45: 467-506, 1989.

5. Iguchi H, Katakami H, Ichinose Y, et al. A case of squamous cell lung carcinoma with high concentration of parathyroid hormonerelated peptide in serum and pleural effusion presenting hypercalcemia. Jpn J Cancer Res 84: 419-424, 1993.

6. Himori T, Ujiie S, Sugawara N, Sugiyama Y, Kanamaru T, Saito
T. Marked leukocytosis in patients with advanced lung cancers. Jpn J Clin. Hematol 18: 187, 1977 (abstract).

7. Suzuki A, Takahashi T, Okuno Y, et al. Analysis of abnormal expression of g-csf gene in a novel tumor cell line (KHC287) elaborating G-CSF, IL-1 and IL-6 with co-amplification of c-myc and c-ki-ras. Int J Cancer 48: 428-433, 1991.

8. Suzuki A, Takahashi T, Okuno Y, et al. IL-1 production as a regulator of G-CSF and IL-6 production in CSF-producing cell lines. Br J Cancer 65: 515-518, 1992.

9. Tsuyuoka R, Takahashi T, Sasaki Y, et al. Colony-stimulating factor-producing tumors: production of granulocyte colonystimulating factor and interleukin-6 is secondary to interleukin-1 production. Eur J Cancer 30A: 2130-2136, 1994.

10. Nanba K, Aoki J, Sasaki N, et al. A new enzyme immunohistochemical technique using alkaline phosphate-labeled avidin and new fuchsin. Byori to Rinshyo 5: 333-339, 1987 (in Japanese with English abstract).

11. Kato H, Kageshita $T$, Maeda $S$, et al. Large cell lung cancer accompanied by remarkable leukocytosis and hypercarcinoma. Clin 
Calcium 14 (6): 142-146, 2004.

12. Uemura Y, Nakata H, Kobayashi M, Harada R, Asahi Y, Taguchi $\mathrm{H}$. Regulation of granulocyte colony-stimulating factor and parathyroid hormone-related protein production in lung carcinoma cell line Oka-C-1. Jpn J Cancer Res 91: 911-917, 2000.

13. Oshika Y, Nakamura M, Ueyama $Y$, et al. A human lung cancer xenograft producing granulocyte-colony stimulating factor and parathyroid hormone-related protein. Oncol Rep 5: 359-362, 1998.

14. Asahi Y, Kubonishi I, Miyoshi I, et al. Establishment of a clonal cell line producing granulocyte colony-stimulating factor and parathyroid hormone-related protein from a lung cancer patient with leukocytosis and hypercalcemia. Jpn J Cancer Res 87 (5): 451458, 1996.

15. Hirano T, Yasukawa K, Harada H, et al. Complementary DNA for a novel human interleukin (BSF-2) that induces B lymphocytes to produce immunoglobulin. Nature 324: 73-76, 1986.

16. Onyia JE, Libermann TA, Bidwell J, et al. Parathyroid hormone (1-34)-mediated interleukin-6 induction. J Cell Biochem 67: 265274, 1997.

17. Shannon MF, Coles LS, Fielke RK, Goodall GJ, Lagnado CA, Vadas MA. Three essential promoter elements mediate tumor necrosis factor and interleukin-1 activation of the granulocyte-colony stimulating factor gene. Growth Factors 7: 181-193, 1992.

18. Kimura M, Hiruma S, Hara S, Hashimoto S. Cytopathology of granulocyte colony-stimulating factor-producing lung adenocarcinoma. Acta Cytol 41: 952-953, 1997.

19. Asanuma N, Hagiwara K, Matsumoto I, et al. PTHrP-producing Tumor: Squamous cell carcinoma of the liver accompanied by humoral hypercalcemia of malignancy, increased IL-6 and leukocytosis. Intern Med 41: 371-376, 2002.

20. Takahashi S, Hakuta M, Aiba K, et al. Elevation of circulating plasma cytokines in cancer patients with high plasma parathyroid hormone-related protein levels. Endocrine-Related Cancer 10: 403407, 2003.

21. Moutabarrik A, Nakanishi I, Ishibashi M. Interleukin-6 and interleukin-6 receptor are expressed by cultured glomerular epithelial cells. Scand J Immunol 40: 181-186, 1994.

22. Akutsu Y. Study of correlation between urinary IL-6 level and mesangial lesion in childhood onset IgA nephropathy. Hokkaido Igaku Zasshi 69: 686-696, 1994.

23. Imashuku S. Differential diagnosis of hemophagocytic syndrome: underlying disorders and selection of the most effective treatment. Int J Hematol 66: 135-151, 1997.

24. Molad Y, Stark P, Prokocimer M, Joshua H, Pinkhas J, Sidi Y. Hemophagocytosis by small cell lung carcinoma. Am J Hematol 36: 154-156, 1991.

(C) 2008 The Japanese Society of Internal Medicine http://www.naika.or.jp/imindex.html 